UCRL-ID-118761

\title{
Energy and Particle Flow in Low Temperature Plasmas
}

\author{
J. N. Bardsley \\ D. W. Hewett \\ P. Vitello
}

March 16, 1995

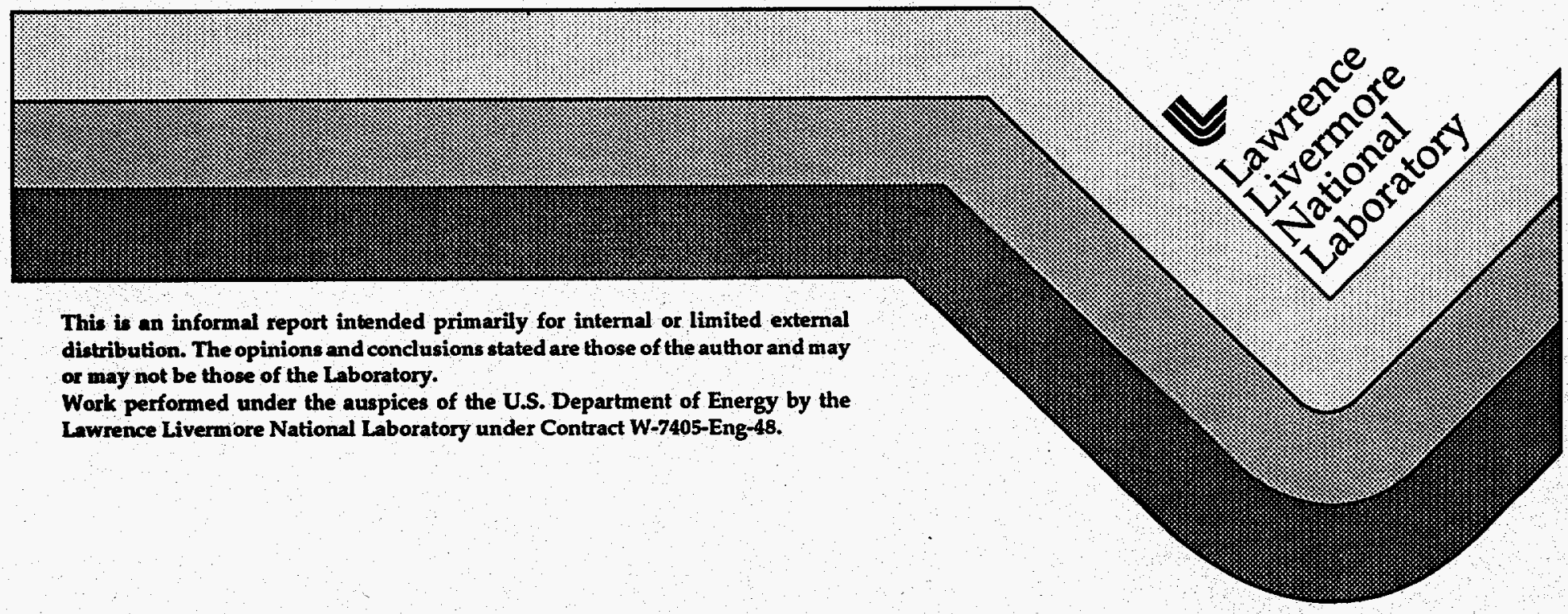




\section{DISCLAIMER}

This document was prepared as an account of work sponsored by an agency of the United States Government. Neither the United States Government nor the University of California nor any of their employees, makes any warranty, express or implied, or assumes any legal liability or responsibility for the accuracy, completeness, or usefulness of any information, apparatus, product, or process disclosed, or represents that its use would not infringe privately owned rights. Reference herein to any specific commercial products, process, or service by trade name, trademark, manufacturer, or otherwise, does not necessarily constitute or imply its endorsement, recommendation, or favoring by the United States Government or the University of Calffornia. The views and opinions of authors expressed herein do not necessarily state or reflect those of the United States Government or the University of California, and shall not be used for advertising or product endorsement purposes.

This report has been reproduced directly from the best available copy.

Available to DOE and DOE contractors from the Office of Scientific and Technical Information

P.O. Box 62, Oak Ridge, TN 37831

Prices available from (615) 576-8401, FTS 626.8401

Available to the public from the

National Technical Information Service

U.S. Department of Commerce

5285 Port Royal Rd.

Springfield, VA 22161 


\section{DISCLAIMER}

Portions of this document may be illegible in electronic image products. Images are produced from the best available original document. 


\title{
Energy and Particle Flow in Low Temperature Plasmas
}

\author{
J. N. Bardsley, D. W. Hewett, and P. Vitello
}

Funding for FY 1993: $\$ 220,000$

Tracking Code 93-SR-098

\begin{abstract}
Increased interest in the development of high density plasma sources for ultra large scale integrated circuit manufacturing with varying geometry and power coupling strategies require the development of 2D models for accurate plasma reactor studies. An objective of our research was to develop a computationally efficient numerical code that would be useful as a design tool for inductively coupled plasma reactors. To achieve that goal we created a 2D fluid model (INDUCT2D) of an argon discharge. As uniformity is a primary issue in wafer manufacturing we have used INDUCT2D to investigate the effect of pressure and reactor geometry on the spatial uniformity of the etching ion flux. We have found that the optimum pressure for maximum uniformity depends upon the spatial profile of the inductive heating, and decreases with the reactor aspect ratio.
\end{abstract}

\section{INTRODUCTION}

A number of new plasma sources are being investigated and used in ultra large scale integrated circuit manufacturing (Lieberman and Gottscho 1993). These sources vary considerably in complexity, method of power coupling, and scalability, but are all capable of producing high plasma densities at low gas pressures. High plasma density $\left(>10^{11} \mathrm{~cm}^{-3}\right)$ is required for high ion flux to surfaces, and hence high throughput in etching and film deposition processes. Low neutral gas pressures (<10 mTorr) are necessary to ensure collisionless ion transport through sheaths for etching high aspect ratio features, such as trenches. The inductively coupled plasma (ICP) source is one type of reactor that is capable of operating under the above desired conditions, with the additional advantage of 
simplicity of design. In particular, no magnetic fields are necessary for its operation, eliminating the need for optimization of the magnet field strengths and configurations. Several recent studies have reported experimental characterization of ICP's (Hopwood et al. 1993; O'Neill et al. 1993).

Associated with the recent interest in high density plasma sources has been a concerted attempt by many researchers to understand the fundamental physics of their operation. Computer modeling has been used extensively for many years to gain insights into low pressure discharge behavior, particularly for the wellstudied radio-frequency ( $\mathrm{rf}$ ) diode reactor. Most of these studies have made use of 1D fluid models or Monte Carlo techniques. Comparisons between these two techniques in if diode simulations have demonstrated that fluid models often provide sufficient accuracy and are able to capture most of the important physics at a fraction of the computational cost of the more exact Monte Carlo technique (Meyyappan and Govidan 1993).

Increased interest in high density sources and varying geometry and power coupling strategies, along with large wafer area processing, and stringent uniformity requirements, require the development of $2 \mathrm{D}$ models for accurate plasma reactor studies. ICP sources require at least $2 \mathrm{D}(\mathrm{r}, \mathrm{z})$ models to describe the power coupling, plasma generation, and plasma transport processes.

\section{RESULTS}

An objective of our research was to develop a computationally efficient numerical code that would be useful as a design tool for ICP reactors. To achieve that goal we created a $2 \mathrm{D}$ fluid model (INDUCT2D) of an argon discharge in an ICP reactor. INDUCT2D can treat generalized reactor geometries, and can be easily extended to include more complex chemical species. The current physics in INDUCT2D, which includes a self-consistent treatment of if power deposition, gives us the new capability of realistically modeling ICP plasma sources. INDUCT2D was developed with speed and accuracy in mind in order that it could be used for parameter space modeling studies.using current workstation computer technology. This was achieved through the use of plasma fluid equations, with an implicit treatment of the short timescale electron temperature and continuity equations, and an explicit scheme for the longer timescale ion 
equations. This, tied to the use of a highly efficient Poisson solver for the electric field, allows INDUCT2D to follow the development of ICP plasmas to their steady state configuration in a matter of hours on a RS/6000 375 workstation.

INDUCT2D has been benchmarked against simple analytic models and with experimental results to verify its accuracy as a modeling tool. As uniformity is a primary issue in wafer manufacturing we have used INDUCT2D to study the effect of pressure and reactor geometry on the spatial uniformity of the etching ion flux. Figure 1 shows how changes in the pressure can affect the density profiles. With increasing pressure, diffusion and thermal conduction become less important leading to larger density and temperature gradients, and highly nonuniform plasmas. We have found that the optimum pressure for maximum uniformity depends upon the spatial profile of the rf heating, and decreases with the reactor aspect ratio.
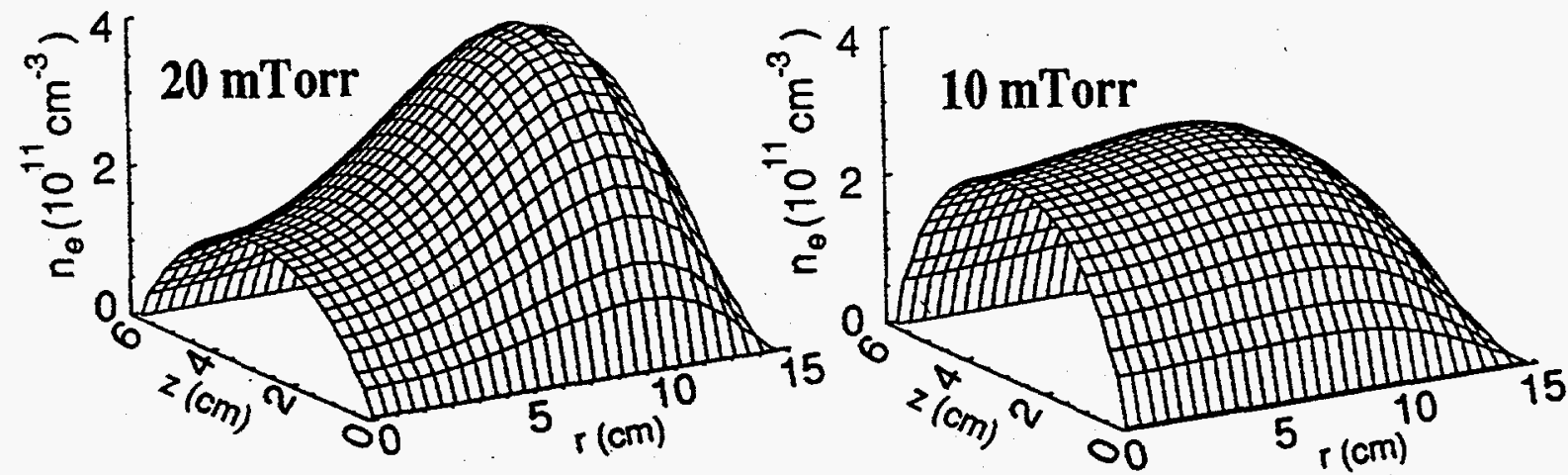

Figure 1. Density profiles for two pressures showing how high pressure leads to off axis, nonuniform peaking of the density. 


\section{REFERENCES}

Hopwood, J., Guarnieri, C. R. Whitehair, S. J., Cuomo, J. J., J. Vac. Sci. Technol. A, 11, 147 (1993).

Lieberman, M. A. and Gottscho, R. A., in Physics of Thin Films, ed. by M. Francombe and J. Vossen, Academic Press (1993).

Meyyappan, M. and Govindan, T. R., J. Appl. Phys., 74, 2250 (1993).

O'Neill, J. A., Barnes, M. S., and Keller, J. H., J. Appl. Phys., 73, 1621 (1993). 